\title{
Performance Evaluation of Meander Line Implantable Antenna integrated with EBG Based Ground for Anatomical Realistic Model
}

\author{
Sadia Sultana and Rinku Basak
}

\begin{abstract}
A unique design and meander line implantable antenna is examined in this paper which satisfies the requirements of ultra-wide band. The designed antenna is integrated with the electromagnetic band gap (EBG) structure based ground plane to enhance the performance. Rectangular electromagnetic band gap (EBG) structures are represented here to evaluate the antenna performance. This compact and efficient MLA antenna is applied to improve the antenna performance for numerous implantable scenarios and biomedical applications. The proposed antenna with EGB ground plane is designed for both the simplified model and anatomical realistic models for the human body and executed the performance in bio-environment. To approve the results of implantable antennas more correctly, simulation is analyzed using anatomical realistic human models. The ultimate design has the whole dimension is $15.2 \times 8.8 \mathrm{~m}^{2}$. The thickness of the antenna is about $0.8 \mathrm{~mm}$. FR4 is chosen as the substrate material and Copper is chosen as the patch material. The antenna is enclosed biocompatible material with silicon inside the tissue in order to protect patient safety. Significant parameters such as S11 parameter, Far field (radiation pattern), VSWR, Efficiency, Directivity, Gain of the proposed antenna have calculated and measured the performance both the simplified and realistic human models. Comparison Analysis of S11 parameter for different substrate materials and patch materials have observed. The radiation mechanism and modified design of the implantable antenna reducing Specific Absorption Rate (SAR) for safety issues. All the simulation results and measurements are obtained from CST Microwave Studio to validate the design.
\end{abstract}

Keywords-Implantable antenna; Meander line Antenna; Electromagnetic Band Gap (EBG); Anatomical Realistic Model; Specific Absorption Rate (SAR).

\section{INTRODUCTION}

The medical sector has observed enormous improvement and enrichment in the current stage. Remote detection of patients is one of such part of the advancement where numerous sickness of the patient can be monitored in a remote

\author{
Sadia Sultana \\ Dept. of MEEE \\ American International University-Bangladesh (AIUB) \\ Dhaka, Bangladesh \\ E-mail: sadiakh102@gmail.com
}

\section{Rinku Basak}

Associate Professor, Dept. of EEE

American International University- Bangladesh (AIUB)

Dhaka, Bangladesh

E-mail: rinku@aiub.edu area. Sensor Based method executes the operation of acquiring the data/info critical signs of the human body as heartbeat rate, blood pressure, temperature etc. And the wearable or implantable antennas transmit this data to the base station.

For dynamic achievement of a total communication network, design of the implantable antenna is essential. Microstrip patch antenna is applicable in biomedical application due to low profile, light weight, optimizable radiation pattern, rigidity, transmission efficiency, and robustness and easy to fabrication. Implantable antennas are implanted into patient body in the different location such as head, arms, chest, hand, legs etc. [1]. Meander line is one kind of microstrip patch antenna. Meander line technology approves the designing of the miniaturized antenna and delivers wideband execution. In a meander line antenna, the wire is folded to reduce the resonant length. Increasing the total wire length in the antenna of fixed axial length lowers its resonant frequency. MLA is proposed in this paper for magnifying the antenna performance [2].

Electromagnetic band gap (EBG) constructions are periodic objects to prevent electromagnetic wave propagation in a given band of frequency. For the reason, particular band gap aspect, specified as a unique type of metamaterial. When these methods are used with patch antennas they contain the excitation of surface wave and also substrate modes and provide a solution to enhance the radiation properties. EBG structure also improves antenna efficiency, gain, bandwidth and reduce mutual coupling [3,4]. In this paper, EBG structure is found in the ground plane of this antenna [5].

Simulation measurement with anatomical realistic body model performs an appropriate form for analyzing the implantable antenna. On the other hand, a simplified body model sometimes shows inappropriate results because of their uniform structure and inaccurate dielectric material [6]. Performance analysis with EBG structure on the antenna ground plane in both models are described in this literature.

For designing biomedical antennas, numerous bands are explored. These bands provide various frequency range for the biomedical applications. The Frequency spectrum is assigned for Industrial, Scientific, and Medical (ISM) is $902-928 \mathrm{MHz}$, $2.4 \mathrm{GHz}$ and 5.7-5.8 $\mathrm{GHz}[7,8]$, for Medical Implant Communication Service (MICS) is 401-406 MHz [9]. $608-$ 
$614 \mathrm{MHz}, 1395$ - $1400 \mathrm{MHz}$, and $1427-1432 \mathrm{MHz}$ are Wireless Medical Telemetry Service (WMTS) bands [10] and 3.1-10.6GHz Ultra Wide Band (UWB) are suggested for implantable medical and biotelemetry.

Ultra Wide Band is chosen for this analysis. Ultra Wide Band offers high-speed over short distances. UWB is applicable for wide area application where obstacles are detected, ultrasound also is feasible in these situations. This purpose generates image organ of human body. The UWB pulse is enough shorter, which is useful for the localization and detection in the medical applications. These UWB features have been appreciated for medical engineering [11].

With the revolutionary advancement in the area of biomedical implants such as cochlear implant cardiac defibrillators and brain neurostimulator etc. can be simply operated by employing RF technology. The implantable antennas are described in two ways like simulators and microsystem. Microsystems are included blood glucose sensor, temperature monitoring, electrocardiograms ECG. And the simulators collect data from the external unit maintained by the doctor like the pacemaker, functional electrical simulators, stimulating specific nerve, retinal implants etc. Interminable development of safety concern and miniaturized proportion of implantable antennas in the biomedical field is increasing day by day. So the proposed antenna in this paper can impose prominent contribution in healthcare and medical sector [12].

This context represents an implantable biomedical antenna which is allocated ultra-wide band. The dimension of the antenna is miniaturized and its directivity is improved using the meandered technique. The main objective of this context is, antenna is placed with EBG structure in ground plane for enhancing the antenna performance and reducing SAR value and performance evaluation for anatomical realistic body models and simplified body models. The designed antenna is enclosed with a biocompatible material for the safety concern. Then the antenna parameters have been determined such as Reflection coefficient or S11, Resonant frequency, Far-field region, Voltage standing wave ratio, and radiation efficiency for both anatomical realistic body model and simplified body model. Finally, SAR has measured whether the antenna is safe to be implanted and the SAR limit $1.6 \mathrm{~W} / \mathrm{kg}$ averaged over $1 \mathrm{~g}$ of tissue from ANSI/ IEEE C95.5 was approved by FCC. [13]

\section{Configuration Of The Antenna}

The configuration of the antenna is based on meander line and spiraling the conductor shape. Meander line antenna is a type of antenna which allows reducing antenna size and imposes wideband communication. The number of turns and position of slots affects the antenna performance. The spiral shape has also many turns which increase effective current flow path length on the patch layer. These factors are responsible for decreasing the operating frequency and can attain a more compact size for an implantable antenna. The antenna must be biocompatible in order to make it suitable for human body tissue. The entire antenna is embedded with biocompatible material silicon to manage safety issues properly. FR4 is used as a substrate material which has loss tangent, $\tan \delta$ of 0.014 , dielectric constant 4.3 and thermal conductivity of $0.3[\mathrm{~W} / \mathrm{K} / \mathrm{m}]$. The EBG array is designed to decrease backward scattering wave towards the body and acted as a high impedance plane for the proposed antenna. The antenna is covering ultra-wideband for this analysis which provides a very different approach to wireless technologies in the biomedical field.

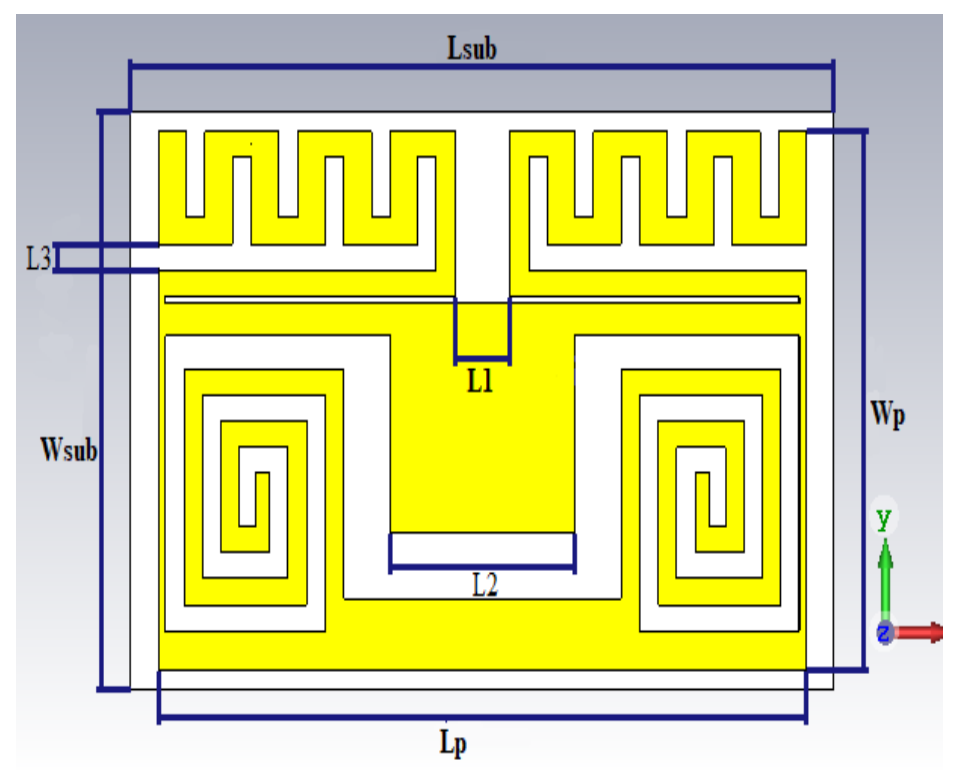

(a)

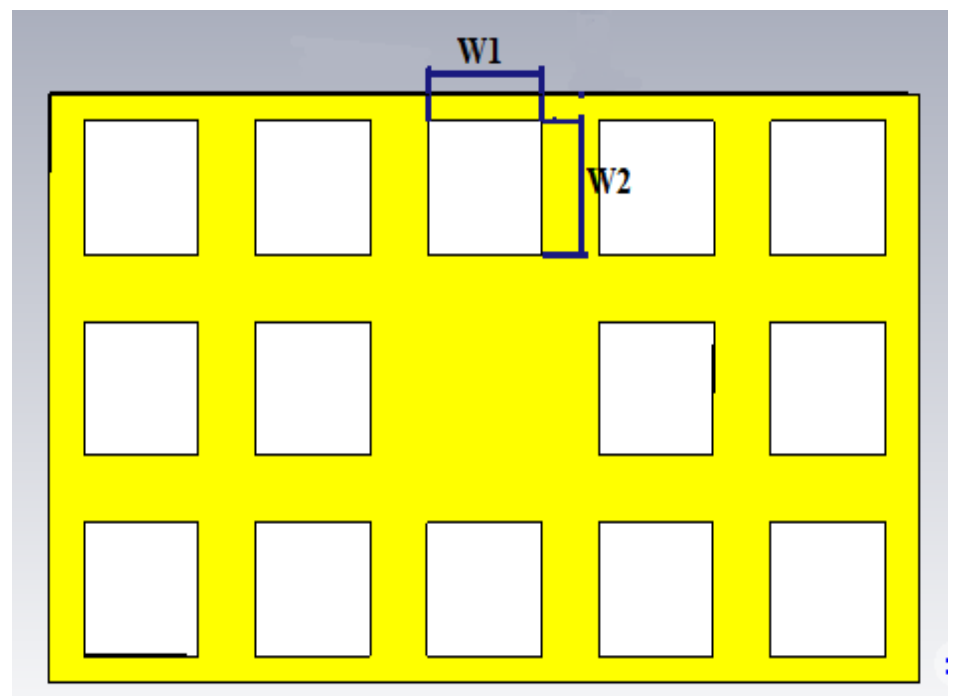

(b)

Fig. 1. Meander line antenna model. (a) Front side and dimensions of the parameter size. (b) Back side. Proposed EBG unit cell integrated with the ground plane and dimensions of the square unit cell. 


\section{ANTENNA DESIGN SPECIFICATIONS}

A flexible rectangular shaped patch antenna is designed by combining spiral and meander lines. Figure 1 shows the antenna is designed to free space in CST Microwave studio which spectacles antenna geometric model, front side and back side of the antenna and antenna is operated at ultrawideband. $15.2 \times 8.8 \times 0.8 \mathrm{~mm}^{3}$ is the actual dimension of the antenna. FR4 is used as the substrate material where substrate length, $\mathrm{Lsub}=15.2 \mathrm{~mm}$, substrate width, Wsub $=8.8 \mathrm{~mm}$, and thickness $=0.53 \mathrm{~mm}$ respectively. FR- 4 material has been chosen for substrate because of its reasonable cost and convenient obtainable in biomedical applications [14-16]. Copper is used as the patch and ground layer where patch length and width are $\mathrm{Lp}=14 \mathrm{~mm}, \mathrm{Wp}=8.2 \mathrm{~mm}$, and thickness $=0.135$ respectively. To develop desired resonance frequency spectrum, other antenna size parameters have been changed. $0.9 \mathrm{~mm}$ feeding pin is inserted between the patch and ground plane and $50 \mathrm{ohms}$ is set for input impedance. Then spiral and meander lines structure is designed for enhancing the efficiency and reducing the operating frequency of the antenna.

The EBG based ground plane is acted High impedance Surface (HIS) to reduce the backward radiation in the human body for implantable antennas. The EBG square unit cell dimension is $2 \times 2 \mathrm{~mm}^{2}$. After free space designing, the antenna is implanted three layers geometric human phantom with encapsulating biocompatible material. Then the antenna is implanted realistic anatomical head phantom (SAM phantom) and hand phantom for determining the performance in CST bio-environment. Optimize the dimensions of antenna size parameter is given Table I [17].

TABLE I.

Dimensions OF The Antenna Size PARAMETER

\begin{tabular}{|c|c|}
\hline Parameter & Size (mm) \\
\hline Lsub & 15.2 \\
\hline Wsub & 8.8 \\
\hline Lp & 14 \\
\hline Wp & 8.2 \\
\hline L1 & 1.2 \\
\hline L2 & 4 \\
\hline L3 & 0.4 \\
\hline W1 & 2 \\
\hline W2 & 2 \\
\hline
\end{tabular}

\section{Simulation Results}

Besides designing the antenna in free space, the antenna performance is evaluating in body in anatomical realistic model and simplified geometric model (skin, fat and muscle). The simulation results are studying in both condition using CST MWS in this section.

\section{A. A simplified body model}

The MLA antenna is designed with EBG method on the basis of tissue implantation with the desired resonance frequency $3.525 \mathrm{GHZ}$ (UWB). Transparent view of multilayer human tissue model as shown in figure 2 where the antenna is embedded with silicon layer for biocompatible and immersed under the skin and fat layer. The muscle layer is created after the silicon layer (biocompatible material). The three layer geometric model are used in simulation studies consists of $3 \mathrm{~mm}$ of skin, $4 \mathrm{~mm}$ of fat, and $8 \mathrm{~mm}$ of muscle tissue arranged as shown in figure 3 . The characteristic of the antenna is implicated by the permittivity, conductivity, density, dielectric constant of the skin, fat and muscle which are given Table II [22].

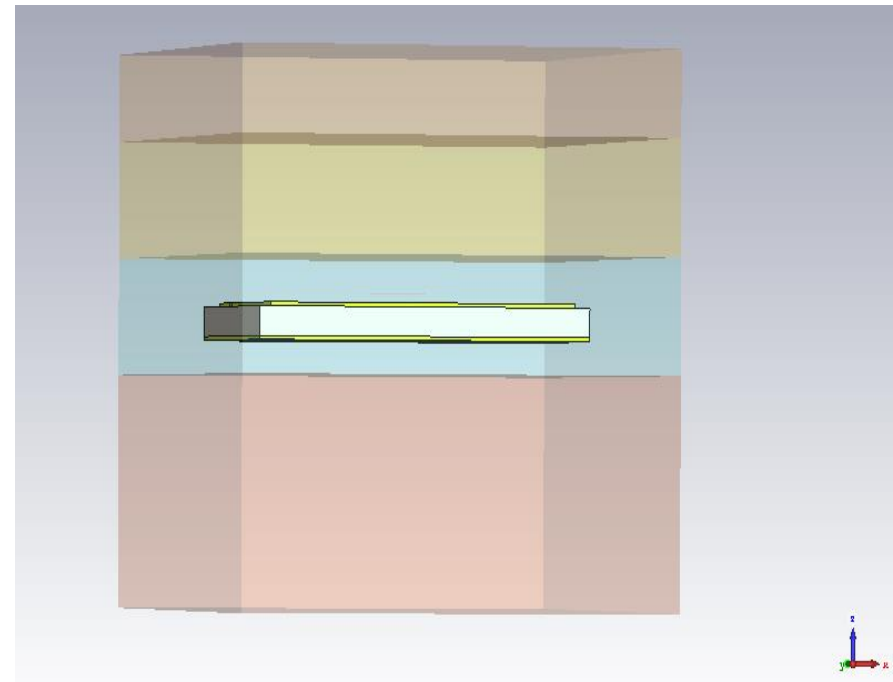

Fig. 2. Transparent view of the antenna inside human tissue model.

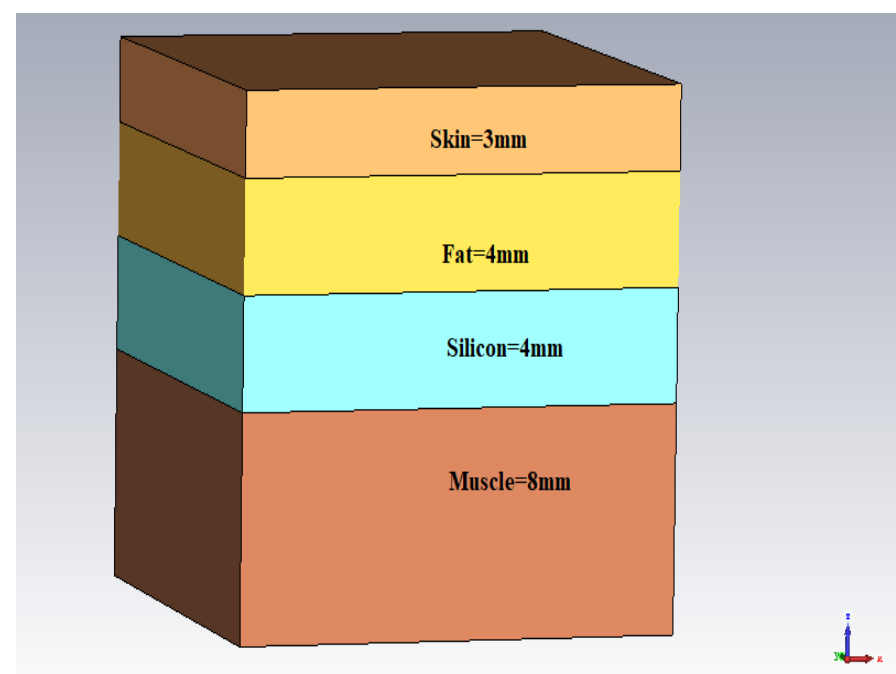

Fig. 3. Layer of the geometric human tissue model. 
Electrical Properties And Thikness Or THREE LAYER GEOMETRIC TISSUE MODEL

\begin{tabular}{|c|c|c|c|c|}
\hline Tissue & Permittivity & $\begin{array}{l}\text { Conductivity } \\
(\mathbf{S} / \mathbf{m})\end{array}$ & $\begin{array}{l}\text { Density } \\
\left(\mathbf{K g} / \mathbf{m}^{3}\right)\end{array}$ & $\begin{array}{l}\text { Thickness } \\
(\mathbf{m m})\end{array}$ \\
\hline Skin & 38.0067 & 1.46407 & 1100 & 3 \\
\hline Fat & 5.171458 & 0.156857 & 910 & 4 \\
\hline Muscle & 54.4176 & 1.88201 & 1040 & 8 \\
\hline
\end{tabular}

\section{B. S11 parameter}

From Fig 4, S11 parameter of the antenna is estimated for simplified human tissue model. S11 parameter is also called return loss or reflection coefficient. The antenna has shown reflection coefficient or S11 parameter $-48.042 \mathrm{~dB}$ at operating frequency $3.525 \mathrm{GHz}$ ultra wideband. S- Parameter or return loss should be kept less than $-10 \mathrm{~dB}$, otherwise about $90 \%$ of the energy is radiated. This parameter of the antenna specifies the amount of power radiated or reflected from the antenna. The bandwidth of the antenna is found $380 \mathrm{MHz}$ $(3.32-3.70 \mathrm{GHz})$ from the curve which is described as the range of frequencies over which the return loss is acceptable.

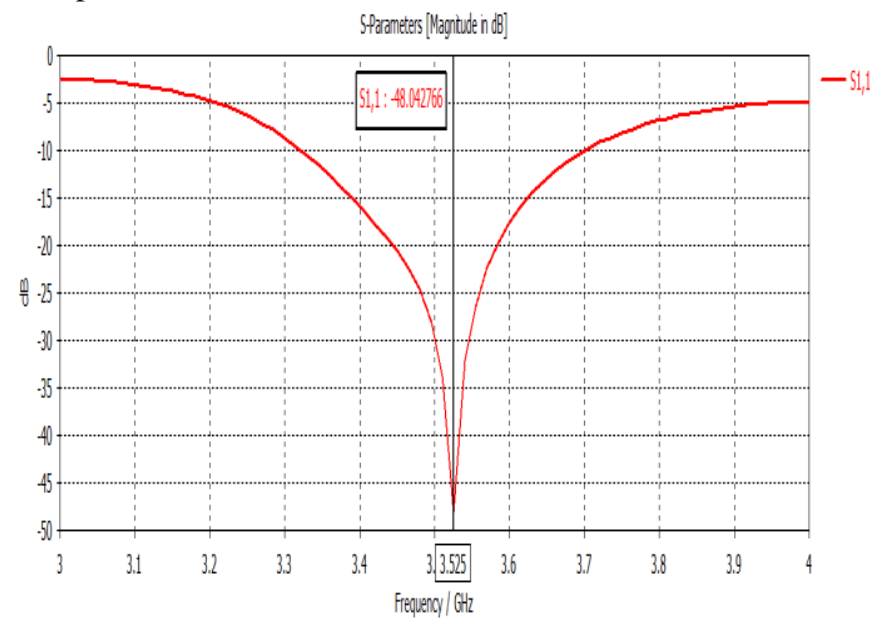

Fig. 4. S11 parameter for the simplified tissue model.

\section{Radiation pattern}

From Fig 5, is illustrated the 3D view of far field region of the meander line antenna for simplified human tissue model. The region which locates far from the antenna is known as the far-field region. In this region, the radiation pattern does not change in shape with distance and this region is influenced by Electric Fields (E-field) and Magnetic fields (H-field). The directivity of the antenna specifies how directional the antenna radiation pattern is. From this figure, directivity of the antenna is found $5.275 \mathrm{dBi}$ which implies that the radiation of the antenna is more focused at that direction. This figure also indicates, the radiation efficiency is $-13.78 \mathrm{~dB}$ and the total radiation efficiency is $13.81 \mathrm{~dB}$ at resonance frequency $3.525 \mathrm{GHz}$.

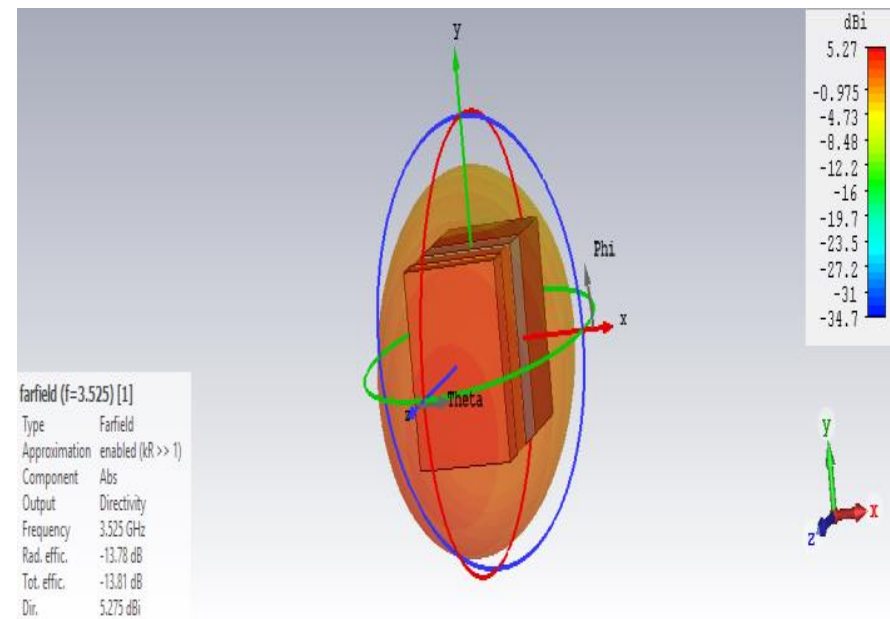

Fig. 5. 3D veiw of far field region of the antenna for simplified tissue model

Fig 6 indicates polar view or 2D veiw of far field region of the antenna. Main lobe is the lobe of the radiation pattern of a antenna which indicates the direction of maximum radiation. This is the lobe that exhibits the greatest field strength. It is also called as main beam. Here, the main lob magnitude is found $5.1 \mathrm{dBi}$ which is centered at 11 degree with an angular width of 110.9 degree. Gain of an antenna interprets the ability to direct or concentrate radio frequency energy in a particular direction or pattern. From this figure, the maximum gain of the antenna is $-8.51 \mathrm{dBi}$ which is focused or received $\mathrm{RF}$ in that direction.

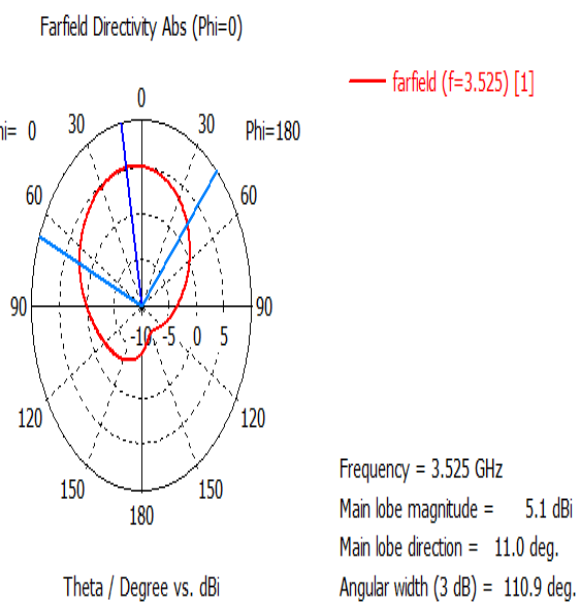

Fig. 6. 2D veiw of far field region of the antenna for simplified tissue model

\section{Specific absorption rate (SAR)}

SAR is a parameter of the antenna which is used to measure the effect of radiation over the human body. SAR 
should maintain the standard limiting value which an antenna is SAR safe and the radiation cannot harmful for the human body. It is a measure of the rate of energy absorption per unit mass at a specific location in the tissue. So, the unit is defined as watts per kilogram $(\mathrm{W} / \mathrm{kg})$. Specific absorption rate is generally measured either over the entire human body or over a limited portion volume (typically $1 \mathrm{~g}$ or $10 \mathrm{~g}$ of tissue). The $1 \mathrm{~g}$ average and $10 \mathrm{~g}$ average specific absorption rate limits are $1.6 \mathrm{~W} / \mathrm{kg}$ and $2 \mathrm{~W} / \mathrm{kg}$ set by FCC and ICNIRP guidelines. The distribution of SAR is $0.44 \mathrm{~W} / \mathrm{kg}$ at $3.352 \mathrm{GHz}$ operating frequency shown in Fig 7 which fulfills the SAR guidelines [13].

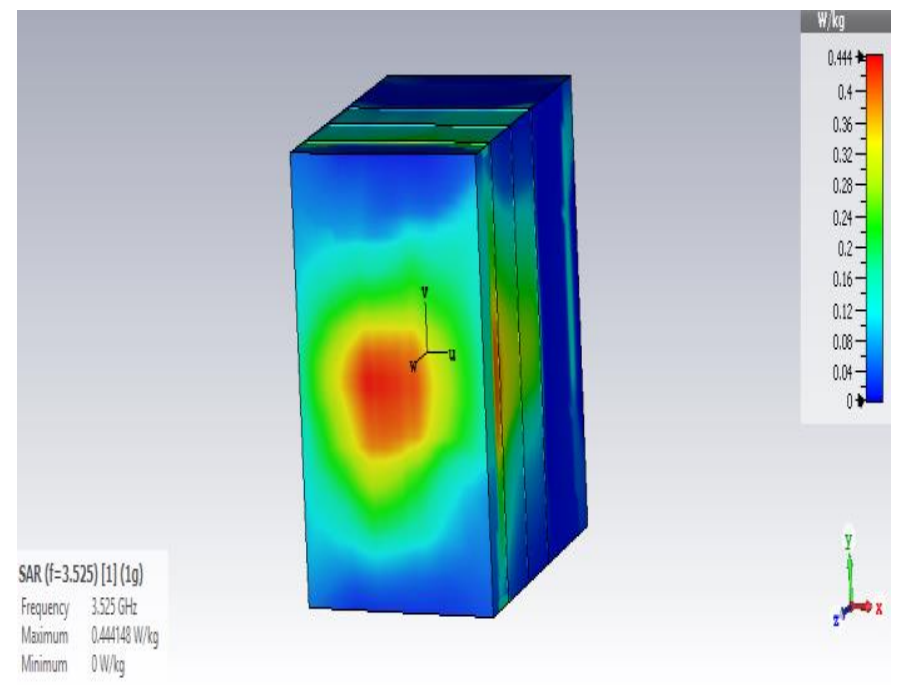

Fig. 7. SAR distribution for the simplified tissue model.

\section{E. . Anatomical realistic body model (SAM phantom)}

The anatomical realistic human models perform significant role in the evaluation of implantable antennas to validate accurate measurement.

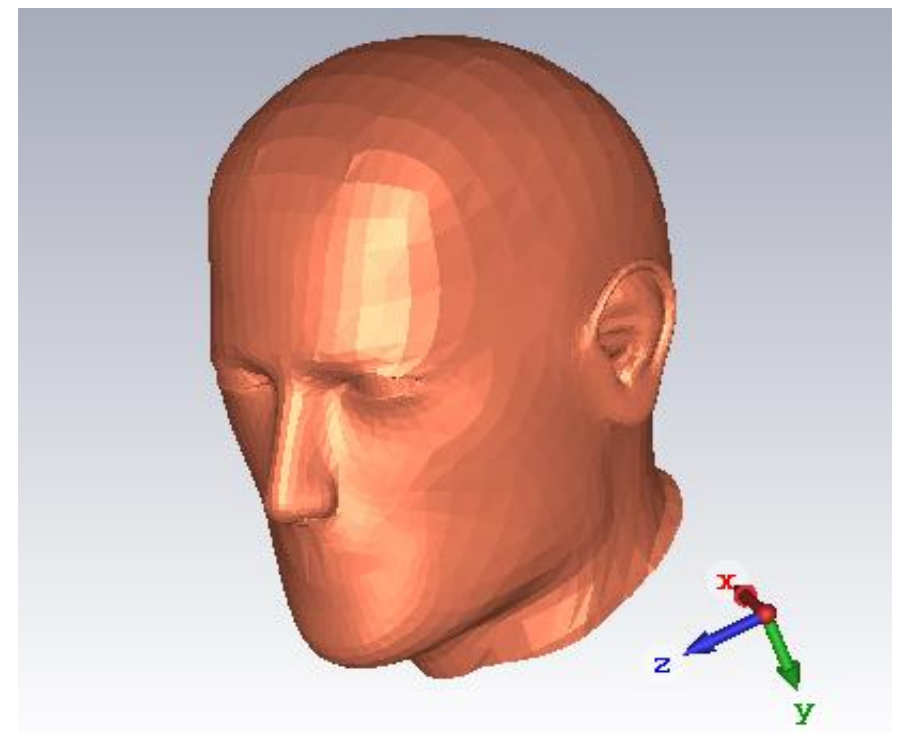

(a)

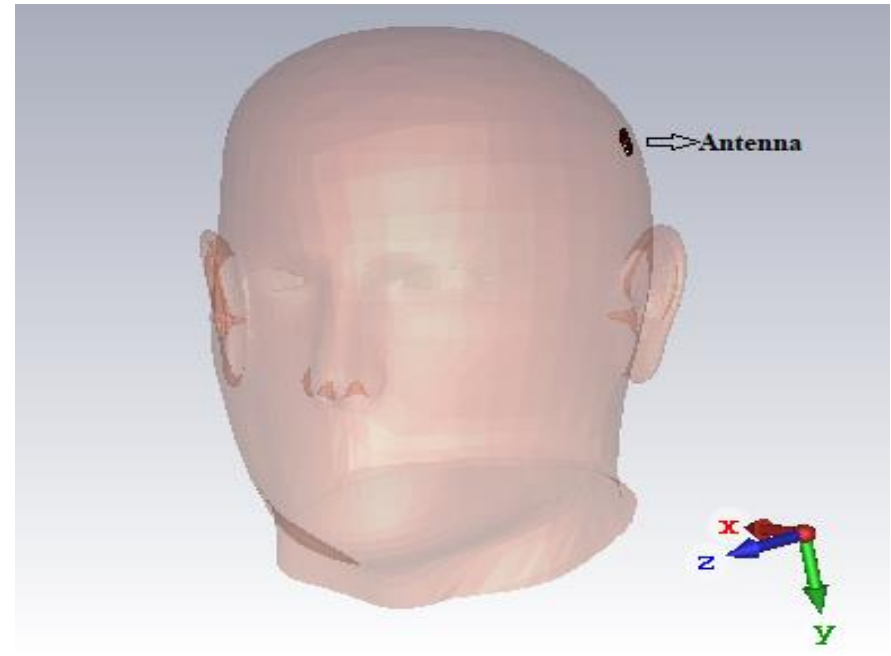

(b)

Fig. 8. (a) SAM phantom, (b) antenna is placed inside the scalp of thie SAM phantom

The Specific Anthropomorphic Mannequin (SAM) phantom is a standard anatomical human model which is used for simulating antenna performance. It provides larger conductivity and permittivity due to multilayer structure. The antenna performance is analyzed where the antenna is placed inside the scalp of this SAM phantom. Fig 8 shows the SAM phantom and also shows the antenna is implanted inside the scalp of this model.

\section{F. S11 parameter}

Antenna performance is measured for anatomical realistic human model or SAM phantom. From Fig 9, S11 parameter is determined of the antenna inside the scalp of SAM phantom. It can be seen from the figure $\mathrm{S} 11$ is $-52.48 \mathrm{~dB}$ at resonance frequency $4.19 \mathrm{GHz}$ which covers the ultra-wideband. It defines the radiated or reflected power of the antenna. The bandwidth is found $\mathrm{MHz} 352 \mathrm{MHz}(3.96-4.31 \mathrm{GHz})$ from the curve from the curve which is described as the range of frequencies over which the return loss is acceptable.

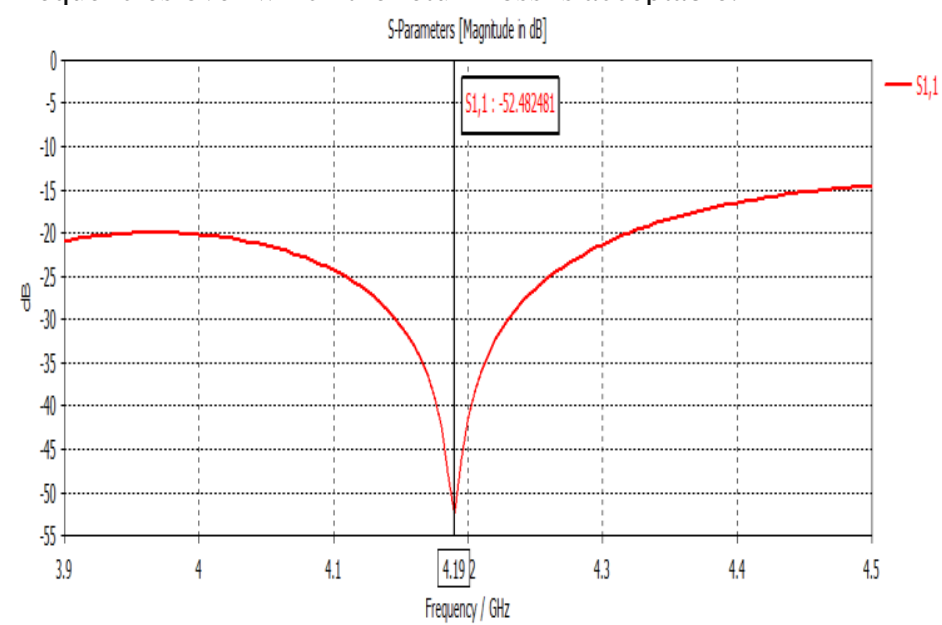

Fig. 9. S11 parameter for SAM model 


\section{G. Radiation pattern}

Figure 10 shows the $3 \mathrm{D}$ view of the far field region of the antenna for SAM phantom. The region which locates far from the antenna is known as the far-field region. In this region, the radiation pattern does not change in shape with distance Directivity of the antenna is found $5.174 \mathrm{dBi}$ which implies that the radiation of the antenna is more focused at that direction and the total radiation efficiency is $-19.66 \mathrm{~dB}$ at $3.525 \mathrm{GHz}$. On the other hand, Figure 11 indicates the polar view of the far field region of the antenna for SAM phantom. It shows the main lob magnitude is $4.8 \mathrm{dBi}$ and the main lob direction is 142 degree where the main lob of the radiation pattern of the antenna is holding maximum radiation. The angular width is 102.1 degree and the maximum antenna gain is $-14.49 \mathrm{dBi}$ which is focused or received $\mathrm{RF}$ in that direction.

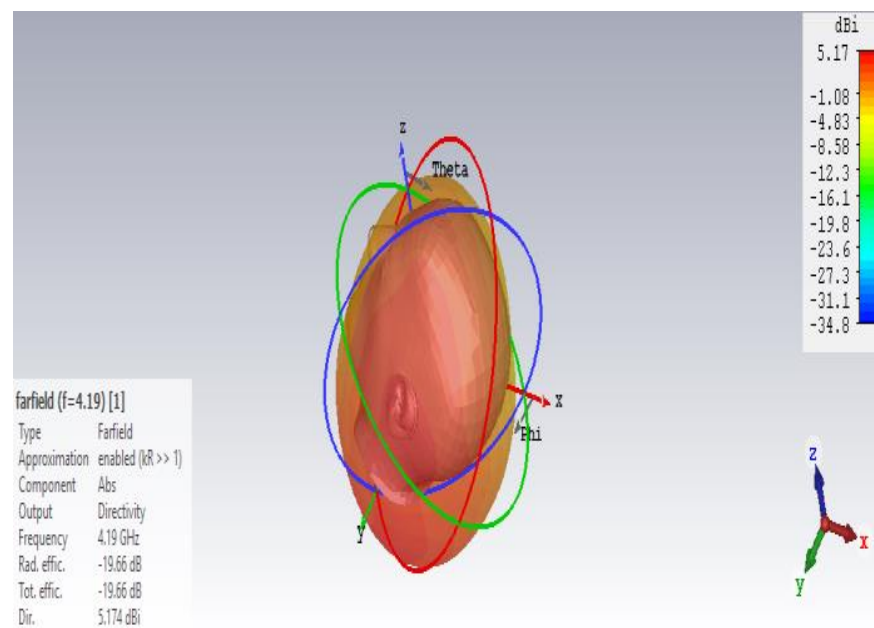

(a)

Fig. 10. (a) 3D veiw of far field region and Polar veiw of the antenna for SAM phantom.

Farfeld Directivity Abs (Phi=0)

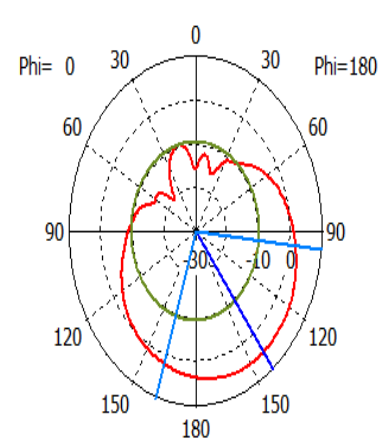

Theta / Degree vs. dBi

(b)

Fig. 11. (a) $2 \mathrm{D}$ veiw of far field region and Polar veiw of the antenna for SAM phantom.

\section{H. Specific absorption rate (SAR)}

The allowance of the rate at which radio frequency energy is ingested by a human tissue from the measuring source is known specific absorption rate (SAR). Figure 12 represents the maximum SAR value of the antenna for anatomical realistic model or SAM phantom. The SAR value is depended heavily on the geometrical portion of the human body that is exposed to the Radio Frequency energy and on the exact location and geometry of the RF source. The Standards for specific absorption rate calculation is approved by IEEE C95.3-2002 standard, where the 1-g average SAR should not exceed $1.6 \mathrm{~W} / \mathrm{kg}$ and $10-\mathrm{g}$ average SAR should not exceed 2 $\mathrm{W} / \mathrm{kg}$ as given by FCC and ICNIRP guidelines. From figure 12 , SAR value is found $0.76 \mathrm{~W} / \mathrm{kg}$ at $4.19 \mathrm{GHz}$ resonance frequency which fulfill the limits of ICNIRP and FCC guidelines regarding SAR (Specific absorption rate) [13].

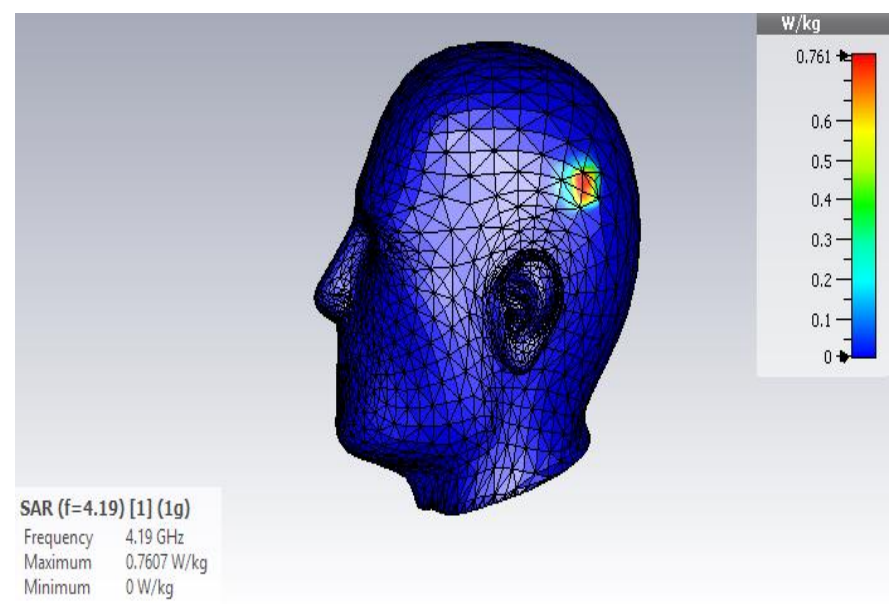

Fig. 12. SAR distribution for SAM phantom

\section{Anatomical realistic body model (Hand phantom)}

The antenna performance is analyzed where the antenna is placed inside the hand phantom. Fig 13 (a) shows the hand phantom and also shows the antenna is implanted inside the skin of hand phantom.

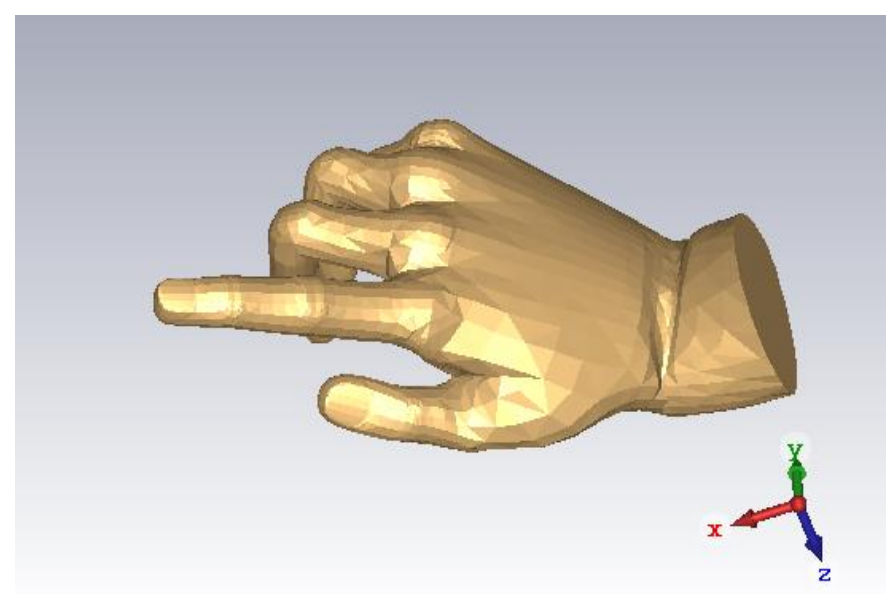

(a) 


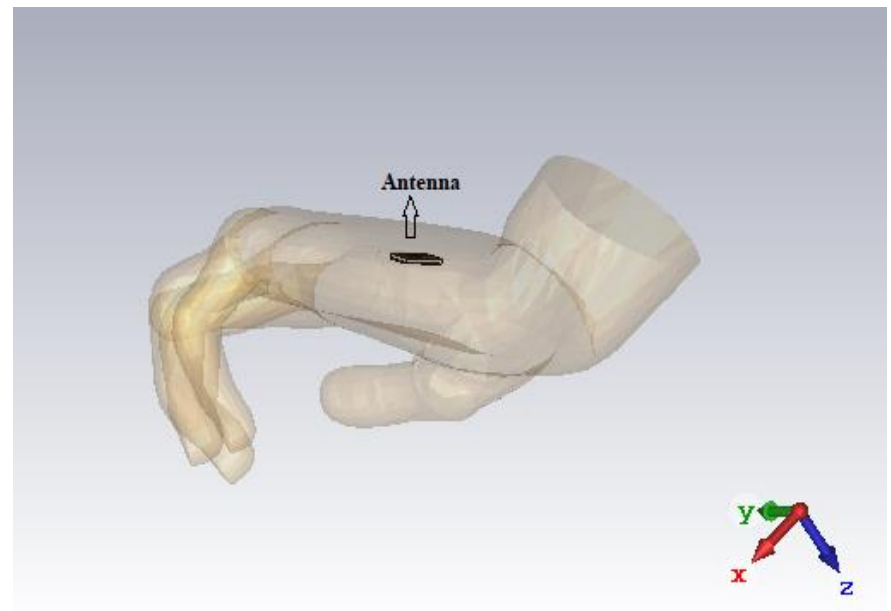

(b)

Fig. 13. (a) Hand phantom, (b) antenna is placed inside the skin of this hand phantom

\section{J. S11 parameter for Anatomical realistic hand phantom}

Fig 14 shows the $\mathrm{S} 11$ parameter is -46.64 at operating frequency $4.79 \mathrm{GHz}$ for hand phantom which covers the UWB. The bandwidth is found $\mathrm{MHz} 254 \mathrm{MHz}$ from the curve from the curve which is described as the range of frequencies over which the return loss is acceptable.

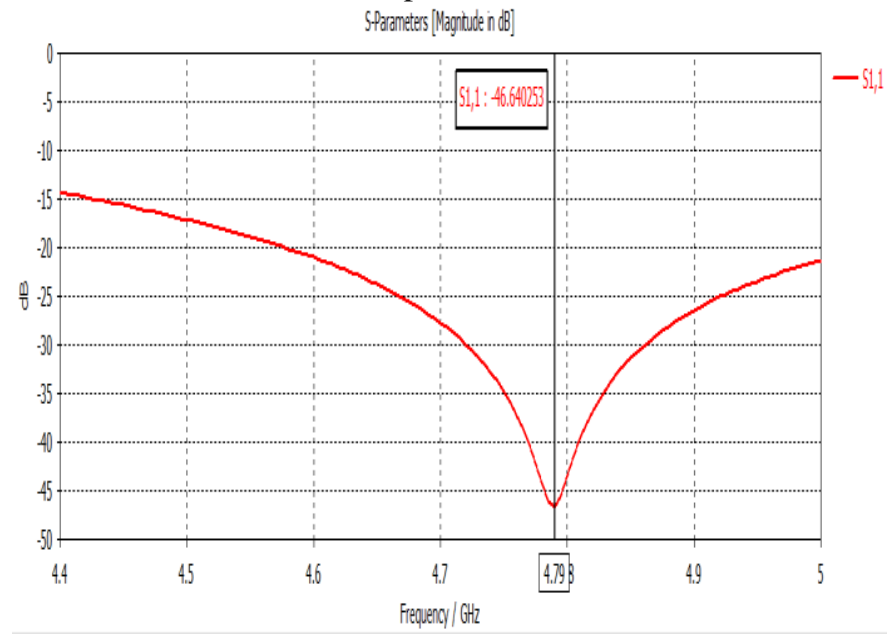

Fig. 14. S11 parameter for hand phantom

\section{K. Radiation pattern}

Figure 15 shows the far field region of the antenna for hand phantom. Directivity is a quantity which defines the ability to concentrate energy in a particular direction and it is directly related to the antenna radiation pattern. Directivity of the antenna is found $5.511 \mathrm{dBi}$ which implies that the radiation of the antenna is more focused at that direction. Antenna efficiency is a coefficient that determines for all the distinctive losses exist in an antenna system. The total radiation efficiency is $-24 \mathrm{~dB}$ at $4.79 \mathrm{GHz}$. Fig 16 demonstrates 2D view or polar view of the antenna for hand phantom. It shows the main lob magnitude is $5.45 \mathrm{dBi}$ and the main lob direction is 140 degree. The angular width is 87.9 degree and the maximum antenna gain is $-14.87 \mathrm{dBi}$ which is focused or received $\mathrm{RF}$ in that direction.

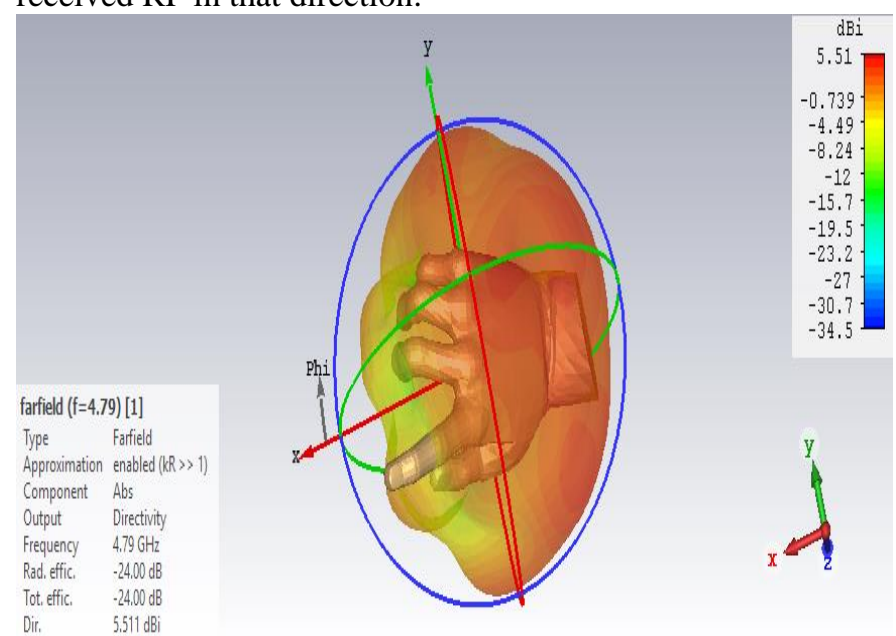

Fig. 15. 3D veiw of far field region of far field region for hand phantom

Farfield Directivity Abs (Phi $=0)$

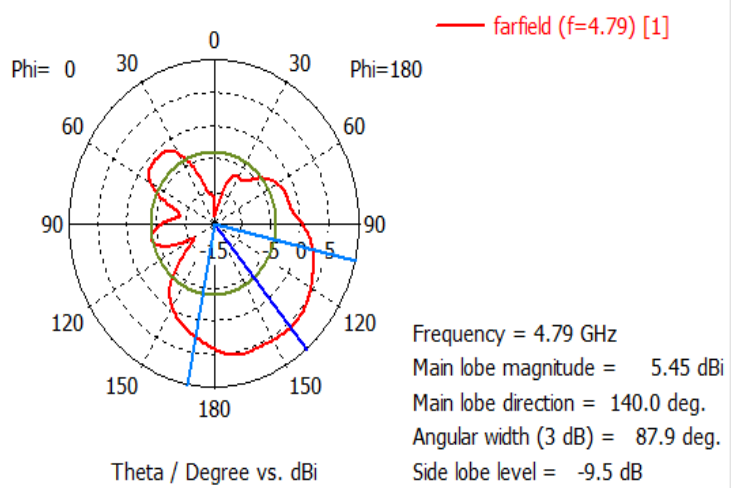

Fig. 16. Polar veiw of the antenna for hand phantom

\section{COMPARISON ANALYSIS}

Table III, IV, V draw the comparison analysis with different ground planes of the proposed antenna among simplified body model, SAM phantom and hand phantom. On the other hand table VI draws the comparison analysis in the aspect of antenna type, $S$ parameter, operating frequency and dimension among the proposed antenna with other existing works.

TABLE III

PERFORMANCE COMPARISON WITH DIFFERENT GROUND PLANES FOR SIMPLIFIED BODY MODEL

\begin{tabular}{|c|c|c|}
\hline Type of parameter & EBG ground & Without EBG ground \\
\hline Resonance frequency $(\mathrm{GHz})$ & 3.525 & 4.41 \\
\hline Bandwidth $(\mathrm{MHz})$ & 380 & 83 \\
\hline S11 $(\mathrm{dB})$ & -48.042 & -22.02 \\
\hline Gain $(\mathrm{max})$ & -8.51 & -12 \\
\hline SAR(W/kg) & 0.444 & 0.61 \\
\hline VSWR & 1.007 & 1.04 \\
\hline Efficiency & -13.81 & -15.63 \\
\hline
\end{tabular}


TABLE IV.

PerformanCe COMParison With DifFERENT GROUND PLANES FOR SAM PHANTOM

\begin{tabular}{|c|c|c|}
\hline Type of parameter & EBG ground & Without EBG ground \\
\hline $\begin{array}{c}\text { Resonance frequency } \\
(\mathrm{GHz})\end{array}$ & 4.19 & 4.32 \\
\hline Bandwidth (MHz) & 352 & 440 \\
\hline S11 (dB) & -52.48 & -15.79 \\
\hline Gain (max) & -14.49 & -14.51 \\
\hline SAR(W/kg) & 0.76 & 1.33 \\
\hline VSWR & 1.004 & 1.39 \\
\hline Efficiency & -19.66 & -19.071 \\
\hline
\end{tabular}

TABLE V

PERFormanCE COMPARISON WITH DIFFERENT Ground Planes fOR HAND PHANTOM

\begin{tabular}{|c|c|c|}
\hline Type of parameter & EBG ground & $\begin{array}{c}\text { Without EBG } \\
\text { ground }\end{array}$ \\
\hline $\begin{array}{c}\text { Resonance frequency } \\
(\mathrm{GHz})\end{array}$ & 4.79 & 6.31 \\
\hline Bandwidth (MHz) & 254 & 85 \\
\hline S11 (dB) & -46.64 & -10.15 \\
\hline Gain (max) & -14.87 & -18.48 \\
\hline SAR(W/kg) & 0.235 & 0.29 \\
\hline VSWR & 1.009 & 1.9 \\
\hline Efficiency & -24 & -20.54 \\
\hline
\end{tabular}

Electromagnetic band gap (EBG) ground structures are broadly used as ground plane in antenna design for developing its radiation characteristics. The return loss of the proposed antenna on the conventional ground plane and EBG ground planes is compared in table III, IV and V. The proposed MLA without EBG ground plane shows higher return loss $(-22.02$ $\mathrm{dB}, 15.79$ and -10.15) whereas the MLA backed EBG ground plane shows lowest return loss $(-48.04,-52.48$ and -46.64). The gain is increased to $-8.51 \mathrm{~dB},-14.49$ and -14.87 as compared to $-12 \mathrm{~dB},-14.51$ and -18.48 for conventional ground plane (without EBG ground plane. From Table III, IV and V, the operating frequency is shifted from $3.525 \mathrm{GHz}$ (simplified body model) to $4.19 \mathrm{GHz}$ and $4.79 \mathrm{GHz}$ (realistic body model) because the antenna is implanted beneath the layer in the anatomical realistic model. The gain value is reduced because the realistic model has larger losses and more lossy tissues. The proposed antenna without EBG ground plane shows relatively higher specific absorption rate. From the tables, it can be also realized that resonance frequency, S parameter, specific absorption rate, bandwidth, gain, VSWR and efficiency are improved in EBG structure for both cases (simplified body model and realistic body model). So, it can be conclude that the designed EBG backed MLA is more efficient over without EBG baked MLA. Table VI draws the comparison analysis in the aspect of Antenna Type, Operating frequency, Dimension, S-parameter among the proposed antenna with other existing work.

\begin{tabular}{|c|c|c|c|c|}
\hline References & $\begin{array}{l}\text { Antenna } \\
\text { Type }\end{array}$ & $\begin{array}{l}\text { Operating } \\
\text { frequency } \\
\mathbf{G H z}\end{array}$ & $\begin{array}{l}\text { Dimensions } \\
\mathbf{m m}^{3}\end{array}$ & \begin{tabular}{l}
\multicolumn{1}{c}{ S11 } \\
Parameter \\
(dB)
\end{tabular} \\
\hline [1] & $\begin{array}{l}\text { AMC backed } \\
\text { MLA }\end{array}$ & 5.3 & 345.6 & -39.5 \\
\hline [4] & $\begin{array}{l}\text { EBG based } \\
\text { microstrip } \\
\text { patch }\end{array}$ & 7.4 & 133.94 & -40.15 \\
\hline [17] & $\begin{array}{l}\text { EBG based } \\
\text { coplanar } \\
\text { patch }\end{array}$ & 5.7 & 31680 & -28 \\
\hline [18] & $\begin{array}{l}\text { EBG based } \\
\text { microstrip } \\
\text { patch }\end{array}$ & 5.86 & 99.28 & -24.6 \\
\hline [19] & MLA & 0.868 & 224.4 & -24.9 \\
\hline [20] & MLA & 0.400 & 67.5 & -25 \\
\hline [21] & $\begin{array}{l}\text { EBG based } \\
\text { loop antenna }\end{array}$ & 1.9 & 9018.75 & -25 \\
\hline This work & $\begin{array}{l}\text { EBG based } \\
\text { MLA }\end{array}$ & 4.19 & 107.008 & -52.48 \\
\hline
\end{tabular}

\section{A. Comparison Analysis for Different Substrate Material}

Fig 17 represents the performance analysis of this proposed antenna with different substrate material for SAM phantom. Five different types of materials as Rogers RO3006, Rogers RO3210, Rogers RT6202, FR4, and Alumina are used in order to observe which one allows a better performance for this antenna. Rogers RO3006, Rogers RO3210, Rogers RT6202, FR4 are obtained inside the ultra-wideband and Alumina is outside of this band. It can be seen that FR4 is obtained lowest return loss and better antenna performance among all other substrate materials.

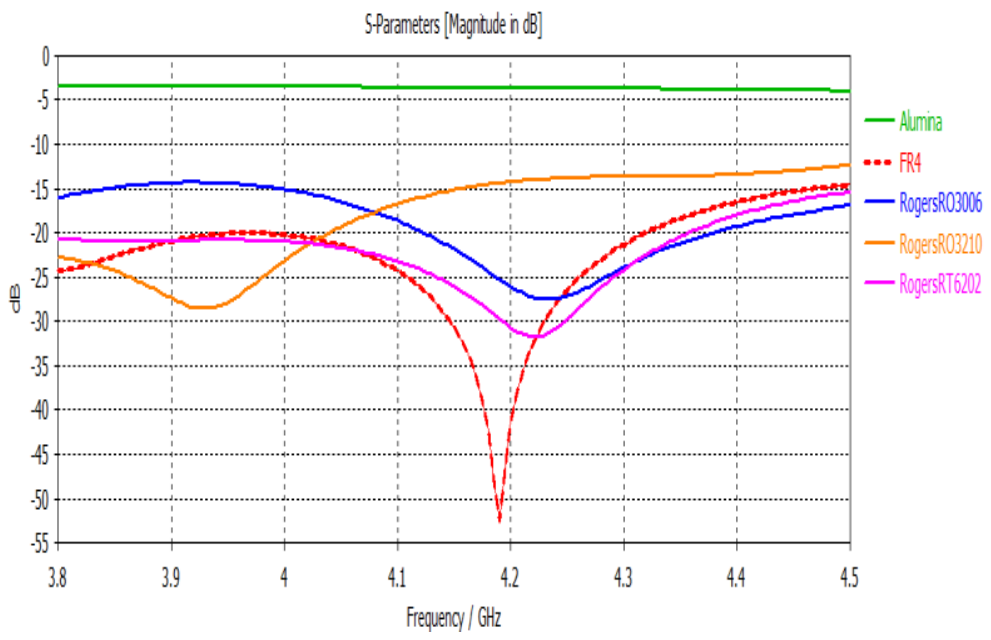

Fig. 17. Comparison of S11 parameter for using different substrate materials for SAM phantom 


\section{B. Comparison Analysis for Different Patch Material}

Fig 18 represents the performance analysis of this proposed antenna with different patch material for SAM phantom. Five different types of materials as Copper, Brass, Lead, Platinum, and Alumina are used for comparison analysis. All the materials are suited inside the band frequency except Alumina and Copper is obtained better antenna performance among all other patch materials.

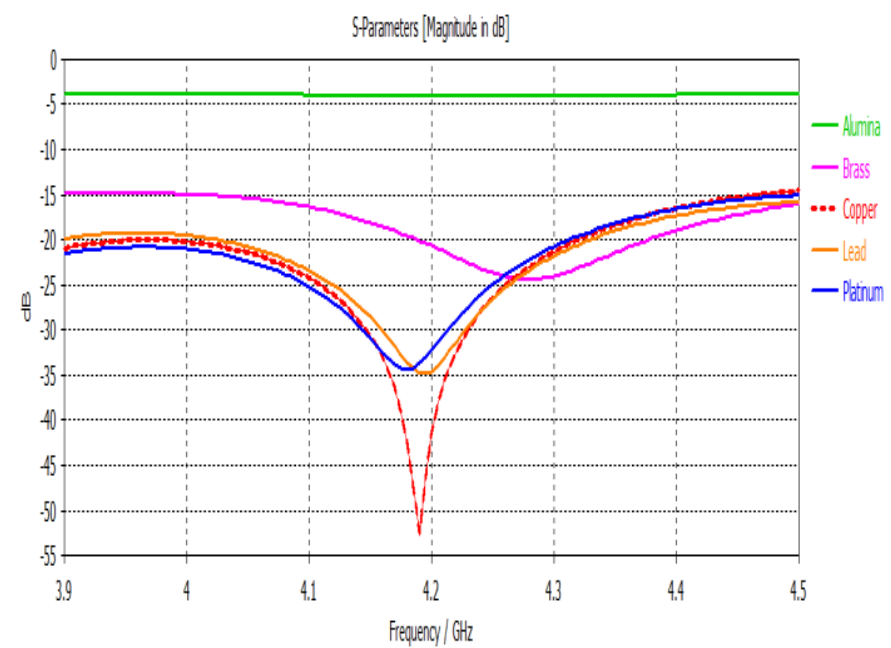

Fig. 18. Comparison of S11 parameter for using different patch materials for SAM phantom.

\section{CONCLUSION}

The paper has demonstrated an implantable meander line antenna integrated with an EBG ground plane that operates at ultra-wide band of interest for biomedical applications. This EBG structure reduces SAR values to improve the antenna performance. This encapsulated biocompatible antenna is implanted both the simplified body model and realistic anatomical model and parameter measurements such as resonant frequency, far-field radiation pattern, total efficiency, SAR are investigated inside the tissue in both body model. For increasing flexibility comparison analysis is examined by changing the substrate material and patch material. Finally, FR4 as the substrate material and Copper as the patch material maintain the better antenna performance. The investigation conducted in this paper will be an important database for the standards establishment of implantable MLA antenna integrated with EBG ground for realistic model in biomedical research.

\section{REFERENCES}

[1] Bhattacharjee, Shankar, et al. "Performance enhancement of meander line antenna with AMC ground for wearable applications." Microwave Conference (APMC), 2016 Asia-Pacific. IEEE, 2016.

[2] Misman, D., et al. "The effect of conductor line to meander line antenna design." Antennas and Propagation Conference, 2008. LAPC 2008. Loughborough. IEEE, 2008.
[3] Ukkonen, Leena, Lauri Sydanheimo, and Markku Kivikoski. "Patch antenna with EBG ground plane and two-layer substrate for passive RFID of metallic objects." Antennas and Propagation Society International Symposium, 2004. IEEE. Vol. 1. IEEE, 2004

[4] Inum, Reefat, et al. "EBG Based Microstrip Patch Antenna for Brain Tumor Detection via Scattering Parameters in Microwave Imaging System." International journal of biomedical imaging 2018 (2018).

[5] Yang, Fan, and Yahya Rahmat-Samii. "Reflection phase characterizations of the EBG ground plane for low profile wire antenna applications." IEEE Transactions on Antennas and Propagation 51.10 (2003): 2691-2703.

[6] Alrawashdeh, R., Yi Huang, and Qian Xu. "Evaluation of Implantable Antennas in Anatomical Body Models." Computer simulation technology (CST AG) 5 (2014).

[7] Yang, Zhi-Jie, et al. "A Circularly Polarized Implantable Antenna for 2.4-GHz ISM Band Biomedical Applications." IEEE Antennas Wirel. Propag. Lett 16 (2017): 2554-2557.

[8] Zhang, Yudi, et al. "A Wideband Circularly Polarized Implantable Antenna for $915 \mathrm{MHz}$ ISM-Band Biotelemetry Devices." IEEE Antennas and Wireless Propagation Letters 17.8 (2018): 1473-1477.

[9] Alt, Eckhard, and John Philip Brinkmann. "Remote control of implantable device through medical implant communication service band." U.S. Patent No. 9,775,532. 3 Oct. 2017

[10] Gieras, Izabella A. "The proliferation of patient-worn wireless telemetry technologies within the US healthcare environment." Information Technology Applications in Biomedicine, 2003. 4th International IEEE EMBS Special Topic Conference on. IEEE, 2003.

[11] Pan, Jianli. "Medical applications of ultra-wideband (uwb)." Survey Paper (2007).

[12] Gandhi, Drishti, and Niraj Kumar. "Wideband Antenna for Medical Application." Optical And Microwave Technologies. Springer, Singapore, 2018. 279-288.

[13] Hwang, Jiunn-Nan, and Fu-Chiarng Chen. "Reduction of the peak SAR in the human head with metamaterials." IEEE Transactions on Antennas and Propagation 54.12 (2006): 3763-3770.

[14] Wasiq, Sumaiya, et al. "Design and simulation of rhombus shaped microstrip patch antenna using HFSS." International Journal of Scientific Research and Management Studies (IJSRMS) 2.2: 97-104.

[15] Warty, Ruchi, et al. "Characterization of implantable antennas for intracranial pressure monitoring: Reflection by and transmission through a scalp phantom." IEEE Transactions on Microwave Theory and Techniques 56.10 (2008): 2366-2376.

[16] Ha, J., K. Kwon, and J. Choi. "Compact zeroth-order resonance antenna for implantable biomedical service applications." Electronics Letters 47.23 (2011): 1267-1269.

[17] Zhu, Shaozhen, and Richard Langley. "Dual-band wearable textile antenna on an EBG substrate." IEEE transactions on Antennas and Propagation 57.4 (2009): 926-935.

[18] Yang, Fan, and Yahya Rahmat-Samii. "Microstrip antennas integrated with electromagnetic band-gap (EBG) structures: A low mutual coupling design for array applications." IEEE transactions on antennas and propagation 51.10 (2003): 2936-2946.

[19] Yang, Wanlan, et al. "A compact dual-band meander-line antenna for biomedical applications." Microwave Workshop Series on RF and Wireless Technologies for Biomedical and Healthcare Applications (IMWS-BIO), 2013 IEEE MTT-S International. IEEE, 2013.

[20] Sallam, Mai O., Ashraf Badawi, and Ezzeldin A. Soliman. "Design of an implantable miniaturized meander line antenna for biomedical telemetry." Antennas and Propagation (EuCAP), 2016 10th European Conference on. IEEE, 2016

[21] Das, Rupam, and Hyoungsuk Yoo. "Application of a Compact Electromagnetic Bandgap Array in a Phone Case for Suppression of Mobile Phone Radiation Exposure." IEEE Transactions on Microwave Theory and Techniques 66.5 (2018): 2363-2372.

[22] Miklavcic, Damijan, Natasa Pavselj, and Francis X. Hart. "Electric properties of tissues." (2006): 3578-3589. 


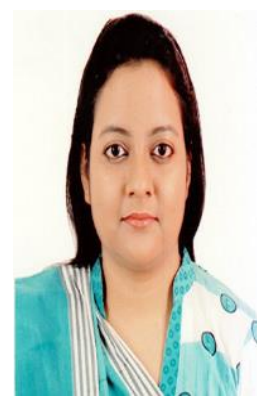

Sadia Sultana received her B.Sc. and M.Sc. in Electrical and Electronic Engineering (EEE) degree from American International University Bangladesh (AIUB) in August 2016 and October 2018 respectively. She was an active member of IEEE AIUB Student Branch and also a member of Engineering Student Association of Bangladesh (ESAB) in 2015.

Her research interest includes microstrip antenna, implantable antenna, electromagnetic band-gap structures, RF and Wireless communication systems and biomedical devices.

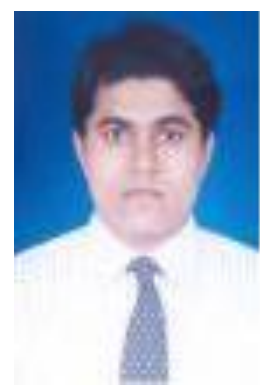

Rinku Basak received his B.Sc. Degree in Electrical and Electronic Engineering from Khulna University of Engineering \& Technology (KUET) in 2004 and M.Sc. Degree in Electrical and Electronic Engineering from Bangladesh University of Engineering \& Technology (BUET) in 2007. His Ph.D degree in Electrical and Electronic Engineering from BUET is ongoing.

Currently he is working as an Associate Professor in the department of Electrical and Electronic Engineering at American International University Bangladesh (AIUB). His research interests include Semiconductor Materials \& Devices, Photonics and Optoelectronics Fiber Optic Communications Electromagnetic Wave Theory and Microwave Communications and Antennas. 